\title{
Ağız ve Diş Sağlığı Programı Öğrencilerinin ve Diş Hekimi Yardımcılarının Yeni Koronavirüs (COVID-19) Bilgi ve Algıları
}

\author{
Şeref Nur Mutlu(0000-0001-9556-3495) ${ }^{\alpha}$, Makbule Bilge Akbulut(0000-0001-9082-3120) ${ }^{\beta}$
}

Selcuk Dent J, 2021; 8: 693-698 (Doi: 10.15311/selcukdentj.773480)

Başvuru Tarihi: 24 Temmuz 2020 Yayına Kabul Tarihi: 20 Ağustos 2020

öz

Ağız ve Diş Sağlığı Programı Öğrencilerinin ve Diş Hekimi Yardımcılarının Yeni Koronavirüs (COVID-19) Bilgi ve Algıları

Amaç: Yeni koronavirüs (COVID-19) tüm dünyada yayılan viral bir pandemidir. Dental işlemlerle oluşan damlacık ve aerosoller hastalığın yayılması açısından hastalar ve sağlık çalışanları için risklidir. Bu çalışmada diş hekimi yardımcılarının ve Ağız ve Diş Sağlığı Programı öğrencilerinin COVID-19 hakkında bilgi ve algı düzeylerinin değerlendirilmesi amaçlanmıştır.

Gereç ve Yöntemler: Anket çalışmamız NEÜ Meslek Yüksekokulu Ağız ve Diş Sağlığı Programı öğrencileri ve Diş Hekimliği Fakültesi kliniklerinde çalışan diş hekimi yardımcılarıyla yapıldı. Verileri toplamak için Google Formlar kullanılarak demografik özelliklerle ilgili 5 soru, COVID-19 bilgi düzeyini ölçmek için 11 soru ve COVID-19 algılarının belirlenmesine yönelik 6 sorunun yer aldığı çevrim içi 22 sorudan oluşan bir anket hazırlandı. Sorular katılımcılara çevrim içi mobil iletişim aracılığı ile gönderildi. Veriler SPSS 22 programı ile analiz edildi.

Bulgular: Anketi \% 78'i kadın, \% 22'si erkek, 18-47 yaş aralığında 118 kişi tamamlamıştır. Genel olarak katıımcıların $\% 90$ 'dan fazlası hastalığın semptomları, bulaşma yolları ve alınması gereken önlemlerin farkındaydı ve COVID-19'un tehlikeli ve ölümcül olduğu kanısındaydı.

Sonuç: Diş hekimi yardımcılarının ve öğrencilerinin COVID19 'la ilgili bilgi seviyesi yeterli olmasına rağmen algı açısından yeterli seviyede bulunmadıkları tespit edilmiştir.

\section{ANAHTAR KELIMELER}

COVID-19, Diş hekimi yardımcıları, Pandemi

Koronavirüsler (CoV), soğuk algınlığı gibi toplumda yaygın görülen, hafif enfeksiyon tablolarından, Orta Doğu Solunum Sendromu (Middle East Respiratory Syndrome, MERS) ve Ağır Akut Solunum Sendromu (Severe Acute Respiratory Syndrome, SARS) gibi daha ciddi enfeksiyon tablolarına neden olabilen büyük bir virüs ailesidir. ${ }^{1}$

Dünya Sağlık Örgütü (DSÖ) Çin Ülke Ofisi, Çin'in Hubei eyaletinin Wuhan şehrinde etiyolojisi bilinmeyen pnömoni vakalarını 31 Aralık 2019'da bildirmiştir. 7 Ocak 2020'de etken daha önce insanlarda tespit edilmemiş yeni bir koronavirüs (2019- nCoV) olarak tanımlanmışıı. Daha sonra 2019-nCoV hastalığının adı COVID-19 olarak kabul

\section{ABSTRACT}

Knowledge and Perception of Oral and Dental Health Program Students and Dental Assistants in New Coronavirus (COVID19)

Background: The new coronavirus (COVID-19) is a viral pandemic that spreads worldwide. Droplets and aerosols formed by dental procedures are risky for patients and healthcare professionals in terms of spread of the disease. In this study, it was aimed to evaluate the knowledge and perception levels of dental assistants and students of Oral and Dental Health Program about COVID-19.

Methods: Our survey was conducted with NEU Vocational School Oral and Dental Health Program students and dental assistants working in the Dentistry Faculty clinics. A questionnaire consisting of 22 questions was prepared using Google Forms to collect the data. The questionnaire included 5 questions about demographic features, 11 questions to determine the level of knowledge of COVID-19 and 6 questions about determining COVID-19 perceptions. The questions were sent to the participants via online communication app. The data were analyzed with SPSS 22 program.

Results: The survey was completed by $78 \%$ female and $22 \%$ male of 118 respondents between the ages of 18-47. In general, more than $90 \%$ of the participants were aware of the symptoms of the disease, the routes of transmission and the precautions to be taken and they believed that COVID-19 was dangerous and fatal.

Conclusion: Although the level of knowledge of dental assistants and students about COVID-19 is sufficient, it has been determined that they are not sufficient in terms of perception.

\section{KEYWORDS}

COVID-19, Dental assistant, Pandemic

edildi, virüs SARS CoV'e yakın benzerliğinden dolayı SARS-CoV-2 olarak isimlendirildi. ${ }^{2}$ DSÖ, 30 Ocak 2020'de COVID-19 salgınını 'uluslararası boyutta halk sağlığı acil durumu' olarak ilan etti, ancak Çin'in dışında 113 ülkede vakaların görülmesi ve hızla yayılması nedeniyle 11 Mart' ta küresel salgın (pandemi) olarak bildirdi. Ülkemizde COVID-19 ile ilgili çalışmalar 10 Ocak'ta başladı ve 22 Ocak'ta T.C. Sağlık Bakanlığı Bilimsel Danışma Kurulu ilk toplantısını gerçekleştirdi ve önlemler aldı. Avrupa ve İran gibi komşu ülkelerden sonra ülkemizde ilk COVID-19 vakası 11 Mart'ta görüldü. ${ }^{1}$

Hızla yayılan bu yeni virüsün SARS ve MERS koronavirüsten daha bulaşıcı olduğu görülmektedir. Bu virüs insandan insana damlacık yoluyla bulaşmaktadır.

\footnotetext{
${ }^{\alpha}$ Necmettin Erbakan Üniversitesi Meram Meslek Yüksekokulu Dişçilik Hizmetleri Bölümü, Konya, Türkiye

$\beta$ Necmettin Erbakan Üniversitesi Diş Hekimliği Fakültesi Endodonti AD, Konya, Türkiye
} 
Hasta bireylerin öksürmesi, hapşırması veya konuşması sırasında solunum salgılarında bulunan virüs, mukozaya doğrudan temas ederse başka bir kişiye bulaşabilir. Ayrıca hasta bireylerin ortama saçtıkları damlacıklara diğer bireylerin elleri ile temas etmesi sonrasında ellerini ağız, burun ve göz mukozasına götürmesi ile de bulaşmaktadır. ${ }^{1}$ Virüs, daha az oranda fekal-oral yolla bulaşmaktadır ancak bu yolun etkili bir bulaş yolu olmadığı düşünülmektedir. ${ }^{1,3}$

COVID-19 hastalarının klinik semptomları farklılıklar göstermektedir. Genel olarak bu hastalığın semptomları; ateş, öksürük, kas ağrısı ve halsizlik, göğüs tomografisinde görülen buzlu cam görüntüsü, şiddetli solunum sıkıntısının yanı sıra daha az görülen semptomları; baş ağrısı, hemoptizi, balgam, diare ve bulantı gibi gastrointestinal bulgulardır. ${ }^{4-5}$

Çok sayıda sağlık personelinin COVID-19 enfekte bireylerle çalışırken hastalığa yakalandığı bilinmektedir. ${ }^{6}$ Diş klinikleri de hastalarla yakın temas ve diş tedavilerinde kullanılan yüksek hızı döner el aletleri ve ultrasoniklerin oluşturduğu aerosoller nedeniyle virüsün yayılması için riskli ortamlardır. ${ }^{7}$ Diş hekiminin yaptığı tedaviler sırasında biyo-aerosol kaynaklarına maruz kalan sağlık çalışanları, bir hastalık veya alerji gelişmesi açısından yüksek risk altındadır. ${ }^{8}$ Diş kliniklerinde koruyucu tedbirleri uygulamak ve sağlık çalışanlarının koruyucu önlemlerini geliştirmek için farkındalık düzeylerini artırmak önemlidir. Bu anket çalışması ile diş hekimi yardımcılarının ve Ağız ve Diş Sağlığı Programı öğrencilerinin COVID-19 ve enfeksiyon kontrolü ile ilgili farkındalık ve algı düzeyinin belirlenmesini amaçlanmaktadır.

\section{GEREÇ VE YÖNTEMLER}

$\mathrm{Bu}$ çalışma insan ve hayvanda herhangi bir girişimsel işlemi içermemektedir ve 'Helsinki Deklerasyon Prensibine' uygun olarak yapılmıştır. Çalışmamız, Necmettin Erbakan Üniversitesi Diş Hekimliği Fakültesi etik kurulu tarafından onaylanmıştır (Protokol no:2020/06).

Çalışmamı için Google Formlar aracılığıyla 22 sorudan oluşan bir anket hazırlandı. Anketin içeriğ çalışmaya başlamadan önce bir endodonti uzmanı, bir periodontoloji uzmanı ve bir istatistikçi tarafından değerlendirildi. Sorular demografik özelliklerin belirlenmesi, COVID-19 bilgi düzeylerinin ve algıların belirlenmesi için ilgili literatür ve uluslararası kılavuzlar gözden geçirilerek üç bölümde hazırlandı. ${ }^{1,2,9}$ Anketin ilk bölümünde demografik özelliklerle ilgili sorular (5 soru), ikinci bölümünde COVID-19 etkeni, kuluçka süresi, bulaşma şekli ve önlemek için gerekli enfeksiyon kontrol yöntemlerini içeren çoktan seçmeli sorular (11 soru) ve son bölümünde COVID-19 algılarının belirlenmesine yönelik sorular (6 soru) yer aldı. Anket çalışmamız Necmettin Erbakan Üniversitesi (NEÜ) Meslek Yüksekokulu Ağız ve Diş Sağlığı
Programı öğrencilerine ve NEÜ Diş Hekimliği Fakültesi kliniklerinde diş hekimi yardımcı personeli olarak çalışan 130 kişiye çevrim içi mobil iletişim aracılığı ile gönderildi. Çalışmamıza 18-47 yaş aralığında 118 kişi katıldı. Çalışmaya dahil olma gönüllülük esasına göre yapıldı.

\section{İstatistiksel Analiz}

Çalışmadan elde ettiğimiz veriler IBM SPSS Statistics 22 (IBM SPSS, Türkiye) istatistiksel analiz programı yardımıyla analiz edildi. Çoklu yanıt içeren maddelerin analizinde multiple response analizinden yararlanıldı. Tespit edilen bulgular arasındaki ilişkinin incelenmesi için Pearson ki-kare testi kullanıldı. Sonuçlar \% 95 güven aralığında $\mathrm{p}<0.05$ istatistiksel olarak anlamlı kabul edildi.

\section{BULGULAR}

Yüz otuz kişiye ulaştırılan ankete 118 kişi dönüş yapmıştır (\% 90.76 cevaplama oranı). Katılımcıların \% 78'i kadın, \% 22'si erkeklerden oluşmaktadır. Katılımcıların ortalama yaşı 21.88 olup yaş aralığı 18 ile 47 arasındadır.

Katılımcıların mesleki deneyimlerinin sorulduğu soruda birden fazla yanıt vermelerine olanak sunuldu. Elde edilen bulgulara göre katılımcıların \% 83.1'i meslek yüksekokulu ağız diş sağlığı programı öğrencisi iken, \% 39'u sağlıkla ilgili lise veya yüksekokul mezunu, $\quad \%$ 11.9'u ise belirtilen programlardan mezun olmayan klinik yardımcılarıdır (Tablo 1).

Tablo 1.

\section{Mesleki deneyim}

\begin{tabular}{|lccc|} 
& \multicolumn{2}{c}{ Yanıtlar } & $\begin{array}{c}\text { Katılımcılar } \\
\text { içindeki \% }\end{array}$ \\
\cline { 2 - 3 } & $\mathbf{n}$ & $\%$ & $\% 83.1$ \\
\hline Meslek Yüksekokulu ADSP öğrencisi & 98 & $\% 62$ & $\% 39$ \\
\hline Sağlıkla ilgili lise veya yüksekokul mezunu & 46 & $\% 29.1$ & $\% 11.9$ \\
\hline $\begin{array}{l}\text { Yukarıda adı geçen programlardan mezun } \\
\text { olmayan klinik yardımcısı }\end{array}$ & 14 & $\% 8.9$ & $\% 133.9$ \\
\hline Toplam & 158 & $\% 100$ & \\
\hline
\end{tabular}

Bilgi Kaynağı

Katılımcıların COVID-19'a ilişkin en yaygın haber kaynağı tercihi \% 85.5 ile haber medyası olurken, \% 76.1'i sosyal medya, \% 60.7'si resmi hükümet web siteleri ve \% 49.6's ise aile ve arkadaşlarını haber kaynağı olarak belirtmiştir.

Katılımcıların \% 13.6'sı $(n=16)$ ailesinde veya çevresinde COVID-19 tanısı alan bir kişi bulunduğunu beyan etmiştir.

\section{COVID-19 hakkında bilgi}

COVID-19'a neden olan virüsün adına ilişkin katılımcıların birden fazla cevap verebilmelerine olanak sağlanmıştır. 118 katılımcıdan toplamda 140 yanıt alınırken, katılımcıların \% 29.7'si $(n=35)$ doğrudan bilmediklerini ifade etmiş, SARS-CoV-2 ise $\quad \%$ 39.8'le $(n=47)$ en yüksek orana ulaşmıştır.

COViD-19'un belirtilerinin sorulduğu ve çoklu yanıt 
verilebilen soruda, çoğunluk sırasıyla ateş (\% 98.3), nefes darlığı (\% 92.4) ve öksürük (\% 86.4) belirti olarak kabul etmiştir. Katılımcılar arasında belirtilere yönelik en düşük görüş ise \% 13.6 ile ciltte döküntü olup onu \% 16.9 ile burun akıntısı ve \% 19.5 ile kırmızı göz takip etmektedir (Tablo 2).

Tablo 2.

\section{COVID-19 belirtilerine verilen cevaplar}

\begin{tabular}{|c|c|c|c|}
\hline & \multicolumn{2}{|c|}{ Yanitlar } & \multirow{2}{*}{$\begin{array}{l}\text { Katılımcıla } \\
\text { içindeki \% }\end{array}$} \\
\hline & $\mathrm{n}$ & $\%$ & \\
\hline Ateş & 116 & \% 14.8 & \% 98.3 \\
\hline Öksürük & 102 & $\% 13$ & $\% 86.4$ \\
\hline Nefes Darlığı & 109 & $\% 13.9$ & $\% 92.4$ \\
\hline Boğaz Ağrısı & 78 & $\% 9.9$ & $\% 66.1$ \\
\hline Baş Ağrısı & 49 & $\% 6.2$ & $\% 41.5$ \\
\hline Kas Ağrısı & 54 & $\% 6.9$ & $\% 45.8$ \\
\hline Tat ve koku alma kaybı & 72 & $\% 9.2$ & $\% 61$ \\
\hline İshal & 46 & $\% 5.9$ & $\% 39$ \\
\hline Burun Tıkanıklığı & 18 & $\% 2.3$ & $\% 15.3$ \\
\hline Burun Akıntısı & 20 & $\% 2.5$ & $\% 16.9$ \\
\hline Kusma & 26 & $\% 3.3$ & $\% 22$ \\
\hline Kırmızı Göz & 23 & $\% 2.9$ & $\% 19.5$ \\
\hline Ciltte Döküntü & 16 & $\% 2$ & $\% 13.6$ \\
\hline Hiç belirti vermeyebilir & 56 & $\% 7.1$ & $\% 47.5$ \\
\hline Toplam & 785 & $\% 100$ & $\% 665.3$ \\
\hline
\end{tabular}

Çoklu cevap verilebilen COVID-19' un bulaşma yollarına ilişkin soruda 482 cevap elde edilmiştir. Sonuçlara göre en yaygın bulaş yolunun \% 96.6'lık bir katılım ile hasta bireyin öksürme, hapşırma ve konuşması esnasında etrafa yayılan küçük parçacıklar aracılığıyla olduğu, ikinci en yaygın bulaş yolunun ise \% 83.8 ile kontamine yüzey ve nesnelere temas ile gerçekleştiği görüşünü ortaya koymaktadır. Katılımcıların en düşük katılım gösterdiği bulaş yolu ise \% 33.3 ile fekal-oral yoldur.

Katılımcıların yakın temasla ilgili verdikleri çoklu cevap seçmeli soruda, en yaygın yakın temas görüşü \% 80.5 $(n=95)$ ile COVID-19 hastasının enfekte sekresyonuna temastır. En az görüş beyan edilen yakın temas nitelendirmesi ise \% 11'lik $(n=13)$ katılım ile COVID-19 hastasına 15 dakika 2 metre mesafede kalmaktır.

İnkübasyon süresi sorulduğunda katılımcıların yarısından fazlası (\% 66.1, n=78), 2-14 gün olduğunu belirtmiştir.

Katılımcılara yöneltilen hangi koşullarda el hijyeni gerekmektedir sorusuna \% 97.5'i $(n=115)$ belirtilen tüm koşullarda gerekli olduğunu beyan ederken, 1 katılımcı yalnızca vücut sıvılarına maruz kalındığında, 2 katılımcı ise yalnızca bir hastaya dokunduktan sonra el hijyeninin sağlanması gerektiğini belirtmiştir.
Kirlenmiş ellerde, el hijyeni için katılımcıların tercih ettiği yöntem en az 20 saniye su ve sabun ile elleri yıkamak olmuştur (\% 81.4, $n=96)$. Katılımcıların \% 5.1'i $(n=6)$ en az 10 saniye su ve sabun ile elleri yıkamanın yeterli olduğunu, \% 13.6'sı $(n=16)$ ise en az \% 60 alkol içerikli dezenfektan ile el hijyenini sağlamak gerektiğini belirtmiştir.

Kliniklerde COVID-19'un bulaşmasını önlemek için elde edilen 831 cevaptan en çok tercih edilen yöntemler kişisel koruyucu ve ekipman kullanmak (\% 95.8), el dezenfektanı kullanmak (\% 93.2) ve ortamdaki kişi sayısını azaltmak (\% 91.5) olarak belirtilmiştir. En az görüş beyan edilen bulaşmanın önlenmesine ilişkin yöntem ise \% 72 ile tıbbi atıkların kontrolüdür (Tablo 3 ).

Tablo 3.

\section{Kliniklerde COVID-19'un bulaşmasını önlemek için yapılması gerekenler}

\begin{tabular}{|c|c|c|c|}
\hline & \multicolumn{2}{|c|}{ Yanitlar } & \multirow{2}{*}{$\begin{array}{l}\text { Katılımcılar } \\
\text { içindeki \% }\end{array}$} \\
\hline & $\mathbf{n}$ & $\%$ & \\
\hline Su ve sabun ile ellerin sık sık yıkanması & 106 & $\% 12.8$ & $\% 89.8$ \\
\hline El dezenfektanı kullanmak & 110 & $\% 13.2$ & $\% 93.2$ \\
\hline Kişisel koruyucu ekipman kullanmak & 113 & $\% 13.6$ & $\% 95.8$ \\
\hline Ortamın havalandırılması & 107 & $\% 12.9$ & $\% 90.7$ \\
\hline Ortamdaki kişi sayısının azaltııması & 108 & $\% 13$ & $\% 91.5$ \\
\hline Tıbbi atıkların kontrolü & 85 & $\% 10.2$ & $\% 72$ \\
\hline $\begin{array}{l}\text { Ortamdaki havanın ve yüzeylerin } \\
\text { dezenfeksiyonu }\end{array}$ & 106 & $\% 12.8$ & $\% 89.8$ \\
\hline $\begin{array}{l}\text { Gerekmedikçe hastaları tedavi gördükleri } \\
\text { kendi bölgelerinden uzaklaştırmaktan ve } \\
\text { taşımaktan kaçınmak }\end{array}$ & 96 & $\% 11.6$ & $\% 81.4$ \\
\hline Toplam & 831 & $\% 100$ & $\% 704.2$ \\
\hline
\end{tabular}

Hastaya dental işlem uygulanırken diş hekimi yardımcı personelinin alması gereken önlemlere ilişkin 1901 görüş elde edilmiştir. Elde edilen sonuçlara göre yardımcı personelin alması gereken önleme ilişkin en yaygın görüş \% 98.3 ile eldiven kullanımı olurken, onu \% 96.6 ile el yıkama ve el dezenfektanı takip etmektedir. En az katılım ise \% 82.2 ile tıbbi atıkların imhası seçeneğine yönelik gerçekleşmiştir. Genel olarak tüm seçeneklere katılım yüksek olmuştur (Tablo 4).

Dental işlem öncesi en yaygın uygulama tercihi \% 55.1'lik ( $n=65)$ katılım ile klorheksidin içeren antiseptik gargara olurken, katılımcıların \% 15.3'ü $(n=18)$ gargara uygulanmasına gerek olmadığını belirtmiştir. 
Tablo 4.

\section{Dental işlemlerde alınması gereken önlemler}

\begin{tabular}{|c|c|c|c|}
\hline & \multicolumn{2}{|c|}{ Yanitlar } & \multirow{2}{*}{$\begin{array}{l}\text { Katılımcıla } \\
\text { içindeki \% }\end{array}$} \\
\hline & $\mathbf{n}$ & $\%$ & \\
\hline El yıkama & 114 & $\% 6$ & $\% 96.6$ \\
\hline El dezenfektanı & 114 & $\% 6$ & $\% 96.6$ \\
\hline Önlük & 111 & $\% 5.8$ & $\% 94.1$ \\
\hline Koruyucu tulum & 97 & $\% 5.1$ & $\% 82.2$ \\
\hline Cerrahi Maske & 102 & $\% 5.4$ & $\% 86.4$ \\
\hline Maske(FFP1/FFP27FFP3 vb.) & 97 & $\% 5.1$ & $\% 82.2$ \\
\hline Eldiven & 116 & $\% 6.1$ & $\% 98.3$ \\
\hline Koruyucu Gözlük & 105 & $\% 5.5$ & 0,89 \\
\hline Bone & 95 & $\% 5$ & $\% 80.5$ \\
\hline Yüz kalkanı & 104 & $\% 5.5$ & $\% 88.1$ \\
\hline Hasta bakım ekipmanlarının sterilizasyonu & 108 & $\% 5.7$ & $\% 91.5$ \\
\hline Ortam yüzeylerinin dezenfeksiyonu & 112 & $\% 5.9$ & $\% 94.9$ \\
\hline Ortamın havalandırılması & 108 & $\% 5.7$ & $\% 91.5$ \\
\hline Ortamdaki kişi sayısının sınırlı tutulması & 107 & $\% 5.6$ & $\% 90.7$ \\
\hline Kişisel hijyenin sürdürülmesi & 109 & $\% 5.7$ & $\% 92.4$ \\
\hline Tıbbi atıkların imhası & 97 & $\% 5.1$ & $\% 82.2$ \\
\hline Hasta izolasyonu & 101 & $\% 5.3$ & $\% 85.6$ \\
\hline Hastanın ateşinin ölçülmesi & 104 & $\% 5.5$ & $\% 88.1$ \\
\hline Toplam & 1901 & $\% 100$ & 16,11 \\
\hline
\end{tabular}

\section{COVID-19 algI}

Katılımcıların büyük çoğunluğu COVID-19 tedavisinin semptomatik olduğunu $\quad$ (\% 94.1), semptomlarının 2-14 günde ortaya çıktığını (\% 88.1), çok tehlikeli (\% 96.6) ve ölümcül olduğunu (\% 92.4) kabul etmiştir. COVID-19'u önlemek için ellerin su ve sabunla yıkanmasının yardımcı olduğu sorusuna \% 78.8 oranında evet cevabı alınmış ve katılımcıların tamamı grip aşısının hastalığı önlemediğini (\% 100) düşünmektedir.

\section{TARTIȘMA}

Çin'de 2019 yılının sonunda başlayan ve dünyada hızla yayılarak küresel salgına neden olan COVID-19'un yayılmasının önüne geçilmesi ve kontrolü için sağlık çalışanlarına önemli sorumluluklar düşmektedir. COVID-19 hakkındaki bilgi ve algılar farklı birimlerde çalışan sağlık personelleri arasında değişebilir. Çalışmamızda NEÜ Diş Hekimliği Fakültesi klinik yardımcıları ve klinik yardımcı olmaya aday olan NEÜ Meslek Yüksekokulu Ağız Diş Sağlığı Programı öğrencilerinin COVID-19 hakkındaki bilgi ve algıları değerlendirilmiştir.

Çin'de 2019 yılının sonunda başlayan ve dünyada hızla yayılarak küresel salgına neden olan COVID-19'un yayılmasının önüne geçilmesi ve kontrolü için sağlık çalışanlarına önemli sorumluluklar düşmektedir. COVID-19 hakkındaki bilgi ve algılar farklı birimlerde çalışan sağlık personelleri arasında değişebilir. Çalışmamızda NEÜ Diş Hekimliği Fakültesi klinik yardımcıları ve klinik yardımcı olmaya aday olan NEÜ Meslek Yüksekokulu Ağız Diş Sağlığı Programı öğrencilerinin COVID-19 hakkındaki bilgi ve algıları değerlendirilmiştir.

Katılımcıların, haber kaynağı olarak sunulan seçenekler arasından, resmi hükümet web sitelerini tercih oranları, haber medyası ve sosyal medyanın gerisindedir. Bu bulgu doğru bilgilerin elde edilmesi açısından kaygı verici olsa da daha önce yapılan çalışmalarla uyumlu bir sonuçtur.9,10 En güvenilir bilgi için, sunulan seçenekler arasında, sağlık çalışanlarının resmi kuruluşların web sitelerini dikkate almaları tavsiye edilebilir.

COVID-19 etkeni olan patojen daha önce insanlarda tespit edilmemiş yeni bir koronavirüs 2019-nCov olarak tanımlanmış ancak virüsün SARS CoV'e yakın benzerliğinden dolayı SARS CoV-2 olarak isimlendirilmiştir. ${ }^{1,2}$ Bu bilgiyi katılımcıların \% 29.7'si bilmediğini ifade etmiştir. Bu soruda verilen doğru cevap oranının düşük olması katılımcıların bilgi kaynağı olarak daha çok haber medyasını ve sosyal medyayı kullanmaları olabilir. Katılımcılardan ailesinde ve yakın çevresinde bu hastalığı geçiren kişilerin oranı azdır, dolayısıyla soruları cevaplarken tecrübelerinin etkili olmadığını düşünmekteyiz.

Bu çalışmada COVID-19 belirtileri hakkında katılımcılar yeterli bilgiye sahipti. En sık görülen belirtiler olan ateş, öksürük ve nefes darlığı belirtilerini tercih oranı, daha az görülen belirtilerden olan baş ağrısı ve ishale göre oldukça yüksek orandadır. Yakın temasla ilgili soruda da katılımcıların doğru bilgilere sahip olduğu tespit edildi. COVID-19 hastasının enfekte sekresyonuna temas ve aynı evde yaşamak en yüksek değerleri almıştır.

COVID-19'un genel olarak inkübasyon süresi 2-14 gün arasında değişmektedir. ${ }^{1,11} \mathrm{Bu}$ soruya katılımcıların büyük çoğunluğu doğru yanıt vermiştir. Şüpheli hastaları tedavi etmek için güvenli sürenin belirlenmesindeki rolü nedeniyle doğru inkübasyon dönemini bilmek önemlidir. ${ }^{12}$

El hijyeni, mikroorganizmaların hastalara bulaşma riskini azaltmak için en önemli kriter olarak kabul edilmiştir. Dental işlemlerde el yıkama her zaman önemli bir basamak olmuştur. Hastaya işlem yapılmadan önce ve sonra, hastaya dokunduktan sonra, kontamine çevre ve ekipmanlara dokunduktan sonra, vücut sıvısına temas olduğunda eller $20 \mathrm{sn}$ boyunca su ve sabunla yıkanmalıdır. Ek olarak, temizlik için alkol içerikli bir antiseptikle ellerin ovularak temizlenmesi de tavsiye edilmektedir. ${ }^{13}$ Çalışmamızda da katılımcılara kirlenmiş ellerde tercih edilen el hijyeni 
yöntemi sorulduğunda, en az 20 sn su ve sabunla elleri yıkamak tercih edilmiş, alkol içerikli dezenfektan kullanımını sadece 16 kişi tercih etmiştir.

Katılımcıların \% 33'ü COVID-19'lu bir hasta tedavi olurken nasıl bir yol izlemeleri gerektiğini bilmediklerini belirtmişler ancak katılımcıların büyük çoğunluğunun, COVID-19'un bulaşmasını önlemek ve dental işlemler yapılırken alınması gereken önlemler konusunda bilgi sahibi oldukları görülmüştür. Katılımcıların COVID-19 pozitif hasta tedavi olurken enfeksiyon kontrol önlemleri açısından bilgi sahipliği beyanları ile mesleki deneyimleri karşılaştırılmıştır. Elde edilen sonuçlara göre klinik yardımcısı olarak görev yapan katılımcıların \% 92.9'u bilgi sahibi olduğunu belirtirken, bu oran öğrenci olan katılımcılarda \% 62.5’tir. İki grubun COVID-19 pozitif hasta tedavisine ilişkin kontrol önlemlerine ilişkin bilgi sahipliği beyanları arasında istatistiksel olarak anlamlı bir farklılık bulunmaktadır $(p<0.05)$. Diş hekimi yardımcı personelinin klinik tecrübelerine bağlı olarak bu konu hakkında bilgi sahibi olmaları normaldir, intiyaca göre öğrenmelerine uygun bir sonuçtur. Katılımcıların büyük çoğunluğunu oluşturan öğrenciler ise, pandemi nedeniyle eğitimlerine ara verildiği ve bu süreçte hasta asiste etmedikleri için, dental tedavi esnasında nasıl bir yol izlemek gerektiğini bilememiş olabilirler.

Dental işlemlerden önce hastaya \% 1'lik hidrojen peroksit veya \% 0.2'lik povidon çözeltisiyle gargara yapılması önerilmektedir. ${ }^{14}$ Diş hekimliğinde yaygın olarak kullanılan klorheksidin içerikli gargaralar ise, oksidatif etkileri olmadığı için COVID-19 üzerinde etkili olmayabilir. ${ }^{14}$ Katılımcıların dental işlemlerden önce kullanılması gereken gargara konusunda yeterli bilgiye sahip olmadıkları ve klorheksidin içerikli gargara kullanımını tercih ettikleri görülmüştür.

Genel olarak katılımcılarının çoğunun algısı COVID19'un tedavisinin semptomatik olduğu, semptomlarının 2-14 günde ortaya çıktığı, çok tehlikeli ve ölümcül olduğu yönündeydi. Katılımcıların tamamı grip aşısının etkili olmadığını kabul ederken, hastalığın önlenmesine yardımcı olan ellerin su ve sabunla yıkanması da katıımcılar tarafından doğru olarak algılanmıştır.

\section{SONUÇ}

Bu çalışmanın sonuçlarına göre, NEÜ diş hekimliği fakültesi klinik yardımcıları ve Ağız ve Diş Sağlığı Programı öğrencileri COVID-19 hastalığıyla ilgili yeterli bilgi düzeyine sahip olmalarına karşın bu hastalıkla ilgili algıları yeterli değildir. Küresel bir tehdit oluşturan COVID-19'la ilgili sağlık çalışanlarının bilgi ve algılarının geliştirilmesi önemlidir. Bu hastalıkla ilgili bilgiler, her gün yenilenen dinamik bir süreçtir. Diş hekimleri ve diş hekimi yardımcıları da güncellenen bilgilerin ve literatürün takibini yapmalıdır. Diş hekimliği fakültelerinde ve diş hekimi yardımclığı eğitimi verilen meslek yüksekokullarında COVID-19 ve benzeri bulaşıcı hastalıklara karşı farkındalık oluşturulmalı, bu ve benzeri hastalıklarla ilgili eğitime önem verilmelidir. 


\section{KAYNAKLAR}

1. T.C. Sağlık Bakanlı̆̆ı Halk Sağlı̆ı Genel Müdürlüğü: COVID-19 (SARS-CoV-2 Enfeksiyonu) Rehberi. Bilim Kurulu Çalışması, T.C. Sağlık Bakanlığı 1 Haziran 2020, Ankara.https://covid19bilgi.saglık.gov.tr/depo/rehberler/c ovid-19-rehberi/COVID-19 Rehberi Genel Bilgiler Epidemiyoloji ve Tanı.pdf.

2. World Health Organization - WHO. Coronavirus disease (COVID-2019) situation reports.2020. Avaliable from: https://www.who.int/emergencies/diseases/novelcoronavirus-2019/situation-reports.

3. Yu P, Zhu J, Han Y, Huang L. A familial cluster of infection associated with the 2019 novel coronavirus indicated potential person-to-person transmission during the incubation period. $\mathrm{J}$ Infect Dis 2020;1757-61.

4. Guan W-j, Ni Z-y, Hu Y, Liang W-h, Ou C-q, He J-x, et al. Clinical characteristics of coronavirus disease 2019 in China. N Engl J Med. 2020;382:1708-20.

5. Jiang F, Deng L, Zhang L, Cai Y, Cheung CW, Xia Z. Review of the clinical characteristics of coronavirus disease 2019 (COVID-19). J Gen Intern Med. 2020:1-5.

6. Secon H. Nearly 3, 400 Chinese healthcare workers gotten the coronavirus, and 13 have died. Business Insider 04 Mar 2020. Avaliable from: businessinsider.com/heathcare-workers-gettingcoronavirus-500-infected-2020-2.

7. Zemouri C, de Soet $\mathrm{H}$, Crielaard W, Laheij A. A scoping review on bio-aerosols in healthcare and the dental enviroment. PLOS one. 2017;12:e0178007.

8. Pankhurst CL, Coulter WA. Do contaminated dental unit waterlines pose a risk of infection? J Dent. 2007;35:71220.,

9. Bhagavathula AS, Aldhaleei WA, Rahmani J, Mahabadi MA, Bandari DK. Knowledge and Perceptions of COVID19 Among Health Care Workers: Cross-Sectional Study. JMIR Public Health Surveill 2020;6:e19160.

10.Fatiregun $A$, Olowookere $S$, Oyebade A. Pandemic Influenza A (H1N1): knowledge among senior health workers at a secondary health care institution in Southwest, Nigeria. Afr Health Sci. 2011;11.

11. Li Q, Guan X, Wu P, Wang X, Zhou L, Tong Y, et al. Early transmission dynamics in Wuhan, China, of novel coronavirus-infected pneumonia. N. Engl. J. Med. 2020;382:1199-1207.

12. Gaffar BO, El Tantawi M, Al-Ansari AA, AIAgl AS, Farooqi FA, Almas KM. Knowledge and practices of dentists regarding MERS-CoV. Saudi J Med Med Sci. 2019;40:714-20.

13. Yan $Y$, Chen H, Chen L, Cheng B, Diao P, Dong L, et al. Consensus of Chinese experts on protection of skin and mucous membrane barrier for health-care workers fighting against coronavirus disease 2019. Dermatol Ther. 2020:e13310.

14.Peng X, Xu X, Li Y, Cheng L, Zhou X, Ren B. Transmission routes of 2019-nCoV and controls in dental practice. Int $\mathrm{J}$ Oral Sci. 2020;12:1-6.
Yazışma Adresi:

Şeref Nur MUTLU

Necmettin Erbakan Üniversitesi

Meram Meslek Yüksekokulu

Dişçilik Hizmetleri Bölümü

Konya, Türkiye

Tel : +903322200026/1140

E Posta: serefnurmutlu@hotmail.com 